ISSN: 2224-0616

Int. J . Agril. Res. Innov. \& Tech. 5(1): 22-27, June, 2015

Available online at http://www.ijarit.webs.com

\title{
GENETIC DIVERGENCE OF J ESSO-BALAM RICE (Oryza sativa L.) OF BANGLADESH
}

\author{
M.S. Ahmed ${ }^{*}$, M.K. Bashar ${ }^{2}$, M. Wazuddin ${ }^{\mathbf{3}}$ and A.K.M. Shamsuddin ${ }^{4}$ \\ Received 13 February 2015, Revised 21 April 2015, Accepted 26 June 2015, Published online 30 June 2015
}

\begin{abstract}
In total 27 genotypes of Jesso-Balam pure line rice germplasm were studied for fourteen morpho-physiological and four physico-chemical characters at Bangladesh Rice Research Institute, during T. Aman 2009 and T. Aman 2011 seasons. According to principal component scores, the two-dimensional scatter diagram $\left(\mathrm{Z}_{1}-\mathrm{Z}_{2}\right)$ has apparently distributed the genotypes into seven clusters. According to Mahalanobis' $\mathrm{D}^{2}$ statistic for the studied characters, the genotypes were clubbed into seven groups. The highest number of genotypes (6) were included in clusters I and III and the lowest two (2) in cluster V and VII. It was also revealed that no duplicate was existed among the genotypes. The intra-cluster distance was maximum (0.77) in cluster III and minimum (0.28) in cluster VII, while the maximum intercluster distance (28.37) was observed between the clusters III and IV and the minimum (2.49) between the clusters I and VII. The cluster V has produced the highest means for plant height $(148.18 \mathrm{~cm})$, straw yield per hill $(39.97 \mathrm{~g})$, panicle length $(28.14 \mathrm{~cm})$ and protein content (9.61\%). But, the cluster IV has showed the highest means for seedling height (69.5 $\mathrm{cm})$, flag and penultimate leaf area $\left(1059.5 \mathrm{~cm}^{2}\right)$, culm diameter $(5.8 \mathrm{~cm})$, filled grain number per panicle (3.64), grain length $(8.63 \mathrm{~mm})$ and 1000 -grain weight $(21.78 \mathrm{~g})$, while the cluster VII had the highest means for grain yield per hill (31.27 g) and effective tiller number per hill (13.5) and the lowest mean for days to maturity (144). Therefore, the genotypes of cluster V need to be crossed with the genotypes of cluster IV or cluster VII, for developing new Balam rice with maximum other good characters. Finally, it could be concluded that the studied J esso-Balam pure lines germplasm is a good source of valuable genes.
\end{abstract}

Keywords: Genetic Divergence, J esso-Balam Rice, Bangladesh

\footnotetext{
${ }^{1}$ Principal Scientific Officer, GRSD, Bangladesh Rice Research Institute, Joydebpur, Gazipur, Bangladesh

${ }^{2}$ Country Manager, Harvest-Plus, CIAT, Banani, Dhaka, Bangladesh

${ }^{3 \& 4}$ Professor, Faculty of Agriculture, Bangladesh Agricultural University, Mymensingh, Bangladesh

*Corresponding author's email: sharfuddin.brri@gmail.com (M.S. Ahmed)
}

\section{Introduction}

Being rice as the staple food in this flooded basin, Bangladesh is one of the largest producers of rice in the world (Anonymous, 2013). Presently, Bangladesh is self sufficient for its production, but still the national average yield is quite low compare to the other countries like China, Japan and South Korea. Moreover, the increasing demand of rice needs to meet with less input and land in future. Besides, changing global climate has negative impact on crop production worldwide. Consequently, rice becomes more important for the resource-poor farmers in unfavourable ecosystems, where other food crops are no longer existed. As a result, high yield with high nutritional and indigenous or traditional values need to be considered for developing new rice varieties in future.

Rice genetic resource is the primary material for rice breeding and makes a concrete contribution to global wealth creation and food security (Zhang et al., 2011). Exploring diversity in a landrace collection is very important for identifying new genes and further improvement of the germplasm (Jayamani et al., 2007; Thomson et al., 2007). Genetic diversity is important for an efficient choice of parents for variety development programs. However, rice diversity in Bangladesh is now threatened due to extensive cultivation of modem varieties (MVs) all over the country along with various intervention of rice habitat (Ahmed et al., 2010). Therefore, it is important to relaunch the old famous local rice varieties like local Balam rice (a kind of Basmoti rice) of southern region by maximizing its yield with valuable traditional traits through hybridization programs for maintaining rice diversity in the field. As long as, limited work has been done on genetic divergence of local rice of Bangladesh. The present study was, therefore, undertaken to assess the extent of genetic diversity in 27 genotypes of J esso-Balam rice germplasm of Bangladesh for selecting prospective parents for developing new promising varieties of Balam rice. 


\section{Materials and Methods}

In total 27 genotypes of Jesso-Balam TAPL (Transplant Aman Pure Line) rice germplasm, developed from a single cross in the hybridization program by Plant Breeding Division, BRRI, through head to raw method, were selected and collected from Rice Gene bank, Bangladesh Rice Research Institute (BRRI), Gazipur, Bangladesh (Table 1) for study of fourteen morphophysiological and four physico-chemical characters. Thirty days old single seedling was transplanted per hill using spaces within and between rows of 20 and $25 \mathrm{~cm}$, respectively for morpho-physiological study during T. Aman 2009 and T. Aman 2011 seasons. Fertilizers were applied @ 60:20:40 kg NPK/ha. Total quantity of TSP and MP were applied before final land preparation. Urea was top dressed at 15, 30 and 45 days after transplanting (DAT). Nine plants from each entry were randomly selected for recording data regarding seedling height, flag and penultimate leaf length and width, plant height, culm diameter, effective tiller number per hill, straw yield per hill, days to maturity, panicle length, primary and secondary branch number per panicle, filled grain number per panicle, grain yield per panicle, grain length, 1000-grain weight and grain yield per hill. Besides, milling outturn, cooking time, amylose and protein content were measured during 2011according to the laboratory manual, Grain Quality and Nutrition Division (GQND), BRRI. Genetic diversity was worked out following principal component analysis (Rao, 1964) and Mahalanobis' (1936) generalized distance $\left(\mathrm{D}^{2}\right)$ analysis extended by Rao (1952). Clustering of genotypes was done according to Tochers method (Rao, 1952). All multivariate analyses were performed in computer using GENSTAT 5.13 program.

Table 1. The list of 27 genotypes of J esso-Balam TAPL with BRRI Genebank accession number

\begin{tabular}{c|c|c|c|c|c|c|c}
\hline $\begin{array}{c}\text { Code } \\
\text { Name* }\end{array}$ & $\begin{array}{c}\text { Accession } \\
\text { number }\end{array}$ & $\begin{array}{c}\text { Code } \\
\text { Name* }\end{array}$ & $\begin{array}{c}\text { Accession } \\
\text { number }\end{array}$ & $\begin{array}{c}\text { Code } \\
\text { Name* }\end{array}$ & $\begin{array}{c}\text { Accession } \\
\text { number }\end{array}$ & $\begin{array}{c}\text { Code } \\
\text { Name* }\end{array}$ & $\begin{array}{c}\text { Accession } \\
\text { number }\end{array}$ \\
\hline JBPL1 & 2470 & JBPL8 & 2458 & JBPL15 & 2480 & JBPL22 & 2477 \\
JBPL2 & 2468 & JBPL9 & 2475 & JBPL16 & 2474 & JBPL23 & 2473 \\
JBPL3 & 2461 & JBPL10 & 2469 & JBPL17 & 2455 & JBPL24 & 2466 \\
JBPL4 & 2457 & JBPL11 & 2462 & JBPL18 & 2463 & JBPL25 & 2454 \\
JBPL5 & 2460 & JBPL12 & 2471 & JBPL19 & 2453 & JBPL26 & 2459 \\
JBPL6 & 2467 & JBPL13 & 2479 & JBPL20 & 2476 & JBPL27 & 2478 \\
JBPL7 & 2465 & JBPL14 & 2464 & JBPL21 & 2472 & & \\
\hline
\end{tabular}

*JBPL=J esso-Balam TAPL.

\section{Results and Discussion}

Analysis of variance has shown highly significant differences among the 27 genotypes for all the 18 morpho-physicochemical characters. The first seven components in the principle component analysis with eigen values $>1$, contributed $85.72 \%$ of the total variations among the genotypes (Table 2). Siddique et al. (2011) and Chakravorty et al. (2013) found the contribution of 77.91 and $75.9 \%$ of the first two and four components to the total variation in rice, respectively. However, Hossain (2008) observed that the first eight axes accounted about $90 \%$ of the total variations by PCA in 78 aromatic and fine grain rice landraces. Based on the values of principal component score 1 and 2 obtained from the principal component analysis, a two-dimensional scatter diagram ( $\mathrm{Z}_{1-}$ $\mathrm{Z}_{2}$ ) using component score 1 as $\mathrm{X}$-axis and component score 2 as Y-axis was constructed (Fig. 1). The genotypes were clubbed apparently into seven clusters indicating the existence of considerable diversity among the genotypes.

Table 2. Latent roots (Eigen value) and their variation for 18 morpho-physicochemical characters of 27J esso-Balam PL rice germplasm

\begin{tabular}{cccc|cccc}
\hline $\begin{array}{c}\text { Principal } \\
\text { component } \\
\text { axes }\end{array}$ & $\begin{array}{c}\text { Latent } \\
\text { roots }\end{array}$ & $\begin{array}{c}\text { Variation } \\
\text { accounted (\%) }\end{array}$ & $\begin{array}{c}\text { Cumulative } \\
\text { variation } \\
\text { (\%) }\end{array}$ & $\begin{array}{c}\text { Principal } \\
\text { component } \\
\text { axes }\end{array}$ & $\begin{array}{c}\text { Latent } \\
\text { roots }\end{array}$ & $\begin{array}{c}\text { Variation } \\
\text { accounted (\%) }\end{array}$ & $\begin{array}{c}\text { Cumulative } \\
\text { variation } \\
(\%)\end{array}$ \\
\hline I & 4.8988 & 27.22 & 27.22 & X & 0.3648 & 2.03 & 94.56 \\
II & 3.4414 & 19.12 & 46.34 & XI & 0.2553 & 1.42 & 95.98 \\
III & 1.9568 & 10.87 & 57.21 & XII & 0.2152 & 1.20 & 97.18 \\
IV & 1.6426 & 9.13 & 66.34 & XIII & 0.1775 & 0.99 & 98.17 \\
V & 1.3223 & 7.35 & 73.69 & XIV & 0.1115 & 0.62 & 98.79 \\
VI & 1.1261 & 6.26 & 79.95 & XV & 0.0829 & 0.46 & 99.25 \\
VII & 1.0388 & 5.77 & 85.72 & XVI & 0.0696 & 0.39 & 99.64 \\
VIII & 0.6354 & 3.53 & 89.25 & XVII & 0.0532 & 0.30 & 99.94 \\
IX & 0.5897 & 3.28 & 92.53 & XVIII & 0.0180 & 0.10 & 100.00 \\
\hline
\end{tabular}




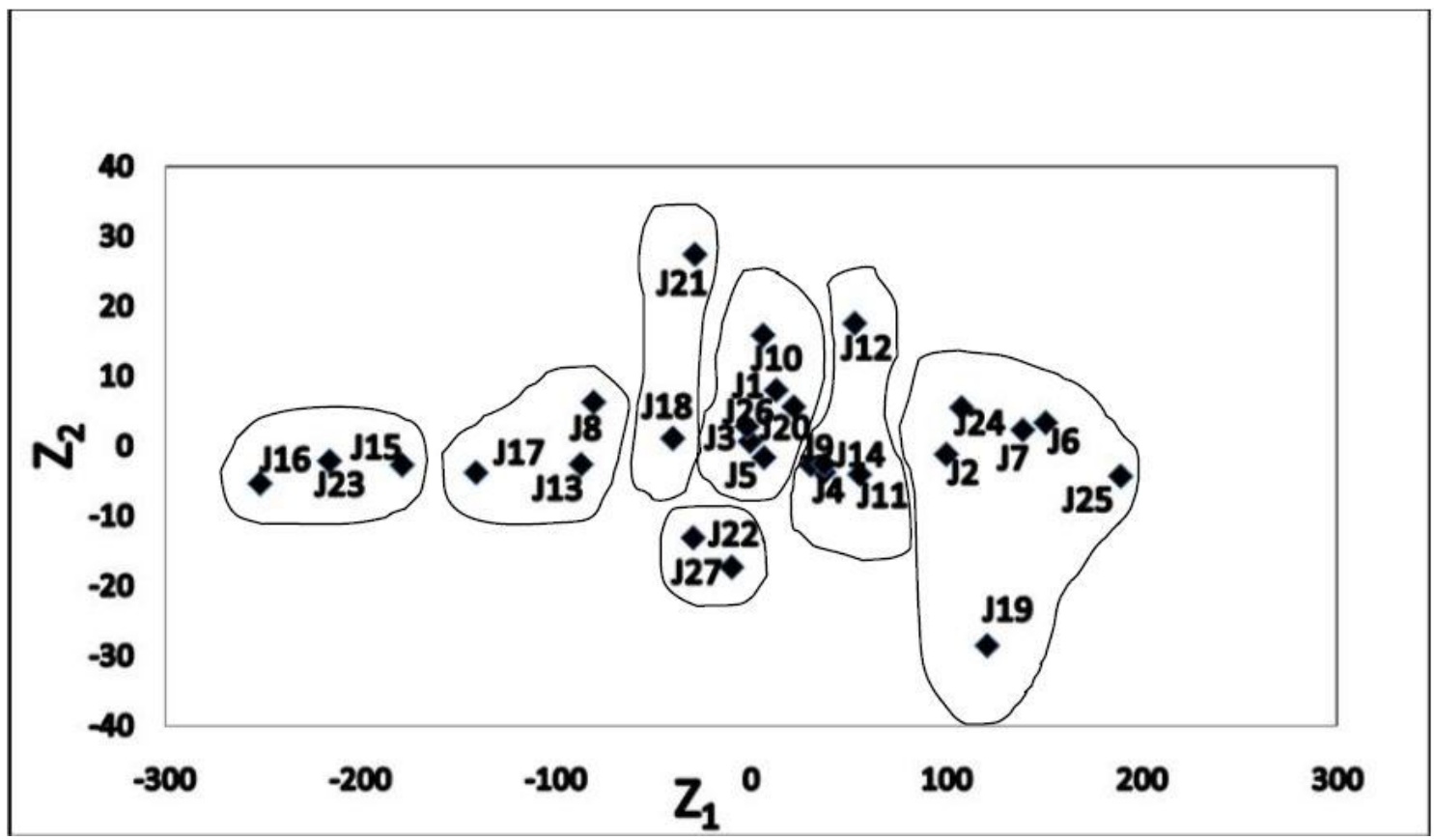

Fig. 1. Two dimensional scatter diagram based on PCA scores for 18 morpho-physicochemical characters of $27 \mathrm{~J}$ esso-Balam PL rice germplasm

The 27 genotypes of Balam rice germplasm yield components. However, Roy et al. (2004) grouped into seven clusters according to non- found five clusters from 35 Aman rice cultivars hierarchal clustering method using Mahalanobis' for 10 traits (characters) during Kharif season. $\mathrm{D}^{2}$ statistic for 18 morphophysico-chemical characters (Table 3). Sohrabi et al. (2012) reported six clusters in 50 Malaysian upland rice accessions for 12 growth characters, yield and

However, the result was in conformity with the cluster pattern of the genotypes obtained though Principal Component Analysis.

Table 3. Distribution of 27 J esso-Balam PL rice germplasm into seven clusters for 18 morphophysicochemical characters

\begin{tabular}{ccl}
\hline Cluster & No. of genotypes & \multicolumn{1}{c}{ Name of genotypes } \\
\hline I & 6 & JBPL1, J BPL3, JBPL5, J BPL10, J BPL20, JBPL26 \\
II & 3 & JBPL8, JBPL13, J BPL17 \\
III & 6 & JBPL2, JBPL6, J BPL7, JBPL19, J BPL24, J BPL25 \\
IV & 3 & JBPL15, J BPL16, JBPL23 \\
V & 2 & JBPL18, J BPL21 \\
VI & 5 & JBPL4, JBPL9, JBPL11, J BPL12, JBPL14 \\
VII & 2 & JBPL22, JBPL27 \\
\hline
\end{tabular}

The inter-genotypic distance $\left(\mathrm{D}^{2}\right)$ was obtained from principal coordinate analysis. The highest inter-genotype distance (1.3940) was observed between the genotypes JBPL13 and JBPL25, followed by 1.3393 between JBPL16 and JBPL25, 1.2416 between J BPL23 and J BPL25. The lowest distance (0.2388) was observed between the genotypes J BPL2 and JBPL6, followed by 0.2801 between JBPL22 and JBPL27, 0.2921 between J BPL1 and JBPL18, respectively.

The distribution pattern of the cluster indicated that the highest number of genotypes (6) included in clusters I and III, followed by five in cluster VI, while the lowest number of genotypes (2) included in clusters V and VII. It also revealed that no duplicate was existed among the genotypes for the studied characters. Similarly, Fukuoka et al. (2006), Hossain (2008), Sarhadi et al. (2009) and Nascimento et al. (2011) earlier also found no duplicates from cluster analysis using Mahalanobis' $\mathrm{D}^{2}$ statistics in rice. The average intra-(bold) and inter-cluster distances $\left(\mathrm{D}^{2}\right)$ are presented in Table 4 . The intra-cluster distance was maximum (0.77) in cluster III and minimum (0.28) in cluster VII, denoting that the genotypes under cluster III were the most diverse 
and those of cluster VII were comparatively similar or less diverse than the genotypes of other clusters. Regarding the inter-cluster distance, maximum genetic distance (28.37) was observed between the clusters III and IV indicating a wide range of diversity, while the minimum distance (2.49) was observed between the clusters I and VII. Mahalingam et al. (2012) found inter-cluster distance ranged from 6.14 to 24.84 , higher than intra-cluster distance ranging from 0.0 to 12.11 for Indian and exotic rice. Hossain (2008) reported intra- and inter-cluster distances ranged from 0.0 to 1.02 and 2.21 to 21.59 , respectively for aromatic and fine grain landraces of rice. Hosan et al. (2010) observed the inter-cluster and intra-cluster distances ranged from 10.58 to 96.76 and 0.50 to 0.76 , respectively in 20 rice landraces.

Table 4. Average intra-(bold) and inter-cluster distances $\left(\mathrm{D}^{2}\right)$ for 18 morpho-physicochemical characters of $27 \mathrm{~J}$ esso-Balam PL rice germplasm

\begin{tabular}{cccccccc}
\hline Clusters & I & II & III & IV & V & VI & VII \\
\hline I & 0.61 & & & & & & \\
II & 9.70 & 0.67 & & & & & \\
III & 8.98 & 18.45 & 0.77 & & & & \\
IV & 19.40 & 10.41 & 28.37 & 0.54 & & & \\
V & 4.81 & 8.30 & 13.01 & 16.22 & 0.41 & & \\
VI & 2.49 & 10.40 & 8.13 & 20.59 & 7.18 & 0.60 & \\
VII & 8.75 & 6.25 & 15.57 & 16.07 & 10.56 & 7.82 & 0.28 \\
\hline
\end{tabular}

The mean values for all the 18 morphophysicochemical characters are presented in Table 5. The data revealed that different clusters exhibited the highest and the lowest mean values of individual characters and none of the cluster showed the highest or lowest mean values of all the characters. The cluster $\mathrm{V}$ with cumulative ranking 1 , produced the highest means for plant height $(148.18 \mathrm{~cm})$, straw yield per hill $(39.97 \mathrm{~g})$, panicle length $(28.14 \mathrm{~cm})$ and protein content (9.61\%). The cluster IV with cumulative ranking
2 , showed the highest means for seedling height $(69.5 \mathrm{~cm})$, flag and penultimate leaf area $(1059.5$ $\left.\mathrm{cm}^{2}\right)$, culm diameter $(5.8 \mathrm{~cm})$, filled grain number per panicle (3.64), grain length $(8.63 \mathrm{~mm})$ and 1000-grain weight (21.78 g), while the cluster VII with cumulative ranking 5 , had the highest means for grain yield per hill ( $31.27 \mathrm{~g}$ ) and effective tiller number per hill (13.5) and the lowest mean for days to maturity (144).

Table 5. Cluster means of $27 \mathrm{~J}$ esso-Balam PL rice germplasm for 18 morpho-physicochemical characters

\begin{tabular}{|c|c|c|c|c|c|c|c|}
\hline Cluster & $\mathrm{I}$ & II & III & IV & V & VI & VII \\
\hline Seedling height (cm) & 69.2 & 67.2 & 64.6 & 69.5 & 67.2 & 65.6 & 64.3 \\
\hline Flag and penultimate leaf area $\left(\mathrm{cm}^{2}\right)$ & 837.2 & 947.2 & 710.6 & 1059.5 & 878.7 & 802.1 & 864.9 \\
\hline Plant height (cm) & 149.7 & 145.5 & 140.9 & 145.1 & 156.0 & 145.9 & 135.1 \\
\hline Culm diameter (mm) & 5.51 & 5.42 & 5.35 & 5.80 & 5.57 & 5.39 & 4.72 \\
\hline Effective tiller number per hill & 11.7 & 11.7 & 11.5 & 10.3 & 12.5 & 11.8 & 13.5 \\
\hline Straw yield per hill (g) & 33.28 & 34.05 & 28.00 & 32.77 & 43.25 & 30.51 & 22.40 \\
\hline Days to maturity & 150.67 & 149.33 & 146.33 & 149.67 & 153.5 & 151 & 144 \\
\hline Panicle length $(\mathrm{cm})$ & 27.7 & 27.1 & 26.9 & 26.4 & 28.1 & 27.3 & 25.6 \\
\hline Total branch number per panicle & 50.0 & 54.3 & 47.2 & 53.7 & 50.0 & 48.2 & 48.5 \\
\hline Filled grain number per panicle & 3.42 & 3.13 & 3.30 & 3.64 & 3.20 & 3.16 & 3.33 \\
\hline Grain yield per panicle (g) & 3.05 & 2.68 & 2.70 & 3.04 & 2.69 & 2.45 & 2.37 \\
\hline Grain length (mm) & 8.26 & 8.58 & 8.15 & 8.63 & 8.16 & 8.33 & 8.41 \\
\hline 1000-grain weight (g) & 20.84 & 21.54 & 20.11 & 21.78 & 19.80 & 20.38 & 19.28 \\
\hline Grain yield per hill (g) & 22.74 & 23.25 & 21.88 & 22.38 & 23.53 & 22.47 & 23.60 \\
\hline Milling outturn (\%) & 71.3 & 71.3 & 73.0 & 71.3 & 72.0 & 71.8 & 72.5 \\
\hline Cooking time (min) & 16.3 & 16.7 & 14.5 & 17.0 & 15.5 & 15.8 & 15.5 \\
\hline Amylose content (\%) & 24.5 & 24.9 & 24.3 & 24.4 & 24.0 & 24.5 & 25.9 \\
\hline Protein content (\%) & 6.90 & 7.53 & 7.47 & 7.03 & 8.05 & 7.38 & 7.95 \\
\hline Cumulative ranking* & 4 & 3 & 6 & 2 & 1 & 7 & 5 \\
\hline
\end{tabular}

*In cumulativeranking, 1 is the most superior cluster for the studied eighteen characters. 
Therefore, if the genotypes of cluster $\mathrm{V}$ are crossed with the genotypes of cluster IV or cluster VII, would exhibit a high heterosis as well as transgressive segregation and would be clubbed the maximum good characters. The inter-cluster distance between the clusters IV and V was 16.22 and between the clusters V and VII was 10.56 indicating moderate distance among the genotypes of these clusters. Besides, moderately diverse genotypes are more suitable in producing desirable variability in the segregating population (Chauhan and Singh, 1982). As a result, the genotypes under clusters V, IV and VII may be selected as parents for future breeding program for developing high yielding J esso-Balam rice variety along with good grain attributes. Hosan et al. (2010), Mahalingam et al. (2012), Sohrabi et al. (2012) and Medhabati et al. (2013) earlier reported similar trend of conclusions using Mahalanobis' $\mathrm{D}^{2}$ statistics on rice.

In the present study, it also appeared from the canonical analysis that $85.67 \%$ of the total variation was accounted for canonical root 1 and $6.33 \%$ by canonical root 2 (Table 6).

Table 6. Values of canonical roots and percentage of variation of 18 morpho-physicochemical characters of 27 Jesso-Balam PL rice germplasm

\begin{tabular}{ccc}
\hline Canonical roots & $\begin{array}{c}\text { Values of } \\
\text { the canonical roots }\end{array}$ & $\begin{array}{c}\text { \% of variation absorbed by } \\
\text { the canonical roots }\end{array}$ \\
\hline 1 & 94.15 & 85.67 \\
2 & 6.95 & 6.33 \\
3 & 4.83 & 4.40 \\
4 & 2.60 & 2.37 \\
5 & 0.93 & 0.85 \\
6 & 0.44 & 0.40 \\
\hline Total & & 100.0 \\
\hline
\end{tabular}

The coefficients pertaining to the different characters in the first two canonical roots are presented in Table 7. It was revealed from canonical variate analysis that grain yield per panicle, 1000-grain weight, grain yield per hill, milling outturn, straw yield per hill and plant height were responsible the most for both the primary and secondary differentiations and contributed maximum to the genetic divergence for the characters studied. Hossain (2008) studied the genetic divergence in 78 aromatic and fine grain landraces of rice genotypes for 18 morpho-physicochemical characters and found that head rice recovery percentage had the highest contribution followed by milling outturn, stem length, elongation ratio, days to flowering and days to maturity in descending order of contribution towards the total divergence among the characters studied. Similarly, Medhabati et al. (2013) by studying the genetic divergence on 37 wild and cultivated rice's for 12 agro morphological characters and observed that the grain yield per plant, spikelet per panicle, 100grain weight, grain length, days to $50 \%$ first flowering, ear bearing tiller/plant and flag leaf length contributed maximum towards genetic divergence.

Table 7. Latent vectors for 18 morpho-physicochemical characters of 27 Jesso-Balam PL rice germplasm

\begin{tabular}{lccc}
\hline Characters & Vector I & Vector II & Combined ranking* \\
\hline Seedling height $(\mathrm{cm})$ & -0.109 & -0.268 & 10 \\
Flag and penultimate leaf area $\left(\mathrm{cm}^{2}\right)$ & -0.074 & +0.009 & 7 \\
Plant height $(\mathrm{cm})$ & +0.193 & +0.098 & 6 \\
Culm diameter (mm) & -5.241 & +3.095 & 16 \\
Effective tiller number per hill & -0.716 & -0.260 & 12 \\
Straw yield per hill (g) & +0.117 & +0.314 & 5 \\
Days to maturity & +0.103 & -0.270 & 14 \\
Paniclelength (cm) & -1.281 & -0.544 & 9 \\
Total branch number per panicle & -0.020 & -0.278 & 17 \\
Filled grain number per panicle & -4.350 & -0.239 & 1 \\
Grain yield per panicle (g) & +2.921 & +2.362 & 18 \\
Grain length (mm) & -6.170 & -5.136 & 2 \\
1000-grain weight (g) & +1.345 & +0.266 & 3 \\
Grain yield per hill (g) & +0.398 & +0.199 & 13 \\
Milling outturn (\%) & +0.552 & -0.054 & 11 \\
Cooking time (min) & -0.674 & -0.355 & 15 \\
Amylose content (\%) & +0.338 & -0.925 & \\
Protein content (\%) & -1.676 & -0.447 &
\end{tabular}


Combined ranking is estimated as higher (1) is the rank with higher sum value of vector I and vector II.

\section{Conclusion}

It could be concluded that the studied JessoBalam PL germplasm is a good source of valuable genes. There is a high degree of diversity existed among the genotypes which needs to be utilized in future varietal improvement/ development programs. Specifically, the genotypes of clusters V, IV and VII may be selected as parents for hybridization programs to develop high yielding Balam rice varieties with desirable other good characters.

\section{Acknowledgement}

The authors are grateful to Head, Genetic Resources and Seed Division, Bangladesh Rice Research Institute, Gazipur for providing financial support and research facilities to conduct this study.

\section{References}

Ahmed, M.S., Akter, K., Khalequzzaman, M., Rashid, E.S.M.H. and Bashar, M.K. 2010. Diversity analysis in Boro rice (Oryza sativa L.) accessions. Bangladesh J. Agril. Res. 35(1): 29-36.

Anonymous. 2013. Adhunik Dhaner Chas (Bangla version). Publication no. 5, 17th Edition. Bangladesh Rice Research Institute, J oydebpur, Gazipur-1701, Bangladesh. p.5.

Chakravorty, A., Ghosh, P.D. and Sahu, P.K. 2013. Multivariate analysis of phenotypic diversity of landraces of rice of West Bengal. American J. Exp. Agric. 3(1): 110-123.

Chauhan, V.S. and Singh, B.B. 1982. Heterosis and genetic variability in relation to genetic divergence in soybean. Indian J. Genet. Plant Breed. 42(2): 324-328.

Fukuoka, S., Suu, T.D., Ebanna, K. and Trinh, L.N. 2006. Diversity in phenotypic profiles in landraces populations of Vietnamese rice: a case study of agronomic characters for conserving crop genetic diversity on farm. Genetic Resources and Crop Evolution 53: 753-761.

Hosan, S.M., Sultana, N., Iftekharuddaula, K.M., Ahmed, M.N.U. and Mia, S. 2010. Genetic divergence in landraces of Bangladesh rice (Oryza sativa L.). The Agriculturists 8(2): 28-34.

Hossain, M.Z. 2008. Genetic diversity study in fine grain and aromatic landraces of rice (Oryza sativa L.) by morphophysicochemical characters and microsatellite DNA markers, Ph.D. Thesis, Department of Genetics and Plant Breeding, BSMRU, Gazipur, Bangladesh. pp. 63-78.
Jayamani, P., Negrao, S., Martins, M., Macas, B. and Oliveira, M.M. 2007. Genetic relatedness of Portuguese rice accessions from diverse origins as assessed by microsatellite markers. Crop Sci. 47(2): 879886.

Mahalanobis, P.C. 1936. On the generalized distance in statistics. Nat. Inst. Sci. India Bull. 2: 49-55.

Mahalingam, A., Saraswathi, R, Ramalingam, J. and Jayaraj, T. 2012. Genetic studies on divergence and phenotypic characterization of indigenous and exotic indica germplasm lines in rice (Oryza sativa L.). African J. Agril. Res. 7(20): 3120-3128.

Medhabati, K., Rohinikumar, M., Sunitibala, H. and Singh, T.D. 2013. Genetic divergence in indigenous wild and cultivated rice species of Manipur valley. ISRN Genetics 2013: 1-6. http:// dx.doi.org/ 10.5402/ 2013/651019

Nascimento, W.F., Silva, E.F. and Veasey, E.A. 2011. Agro-morphological characterization of upland rice accessions. Sci. Agric. 68(6): 652-660.

Rao, C.R. 1952. Advance statistical methods in Biometrical Research. John Willey and Sons Inc., New York, USA. pp. 45-110.

Rao, C.R. 1964. The use and interception of principal component analysis in applied research. Sankhya. Ser. A. 22: 317-318.

Roy, S.K., Kundu, A., Chand, S.P. and Senapati, B.K. 2004. Diversity of panicle characters in Aman rice (Oryza sativa L.). Environ. Ecol. 22(Spl-3): 500-503.

Sarhadi, W.A., Ookawa, T., Yoshihashi, T., Madadi, A.K., Yosofzai, W., Oikawa, Y. and Hirata, Y. 2009. Characterization of aroma and agronomic traits in Afghan native rice cultivars. Plant Prod. Sci. 12: 63-69.

Siddique, M.A., Islam, M.Z, Khalequzzaman M. and Ahmed, M.S. 2011. Genetic diversity in rice (Oryza sativa L.) landraces of hilly areas in Bangladesh. Bangladesh J. Plant Breed. Genet. 24(2): 25-30.

Sohrabi, M., Rafii, M.Y., Hanafi, M.M., Akmar, A.S.N. and Latif, M.A. 2012. Genetic diversity of upland rice germplasm in Malaysia based on quantitative traits. The Sci. World J. 12: 1-9.

Thomson, M.J., Septiningsih, E.M., Suwardjo, F., Santoso, T.S., Silitonga, T.S. and McCouch, S.R. 2007. Genetic diversity analysis of traditional and improved Indonesian rice (Oryza sativa L.) germplasm using microsatellite markers. Theor. Appl. Genet. 114(3): 559-568.

Zhang, P., Jinquan, L., Xiaoling, L., Xiangdong, L., Xingjuan, Z. and Yonggen, L. 2011. Population structure and genetic diversity in a rice core collection (Oryza sativa L.) investigated with SSR markers. PLOS ONE 6(12): 1-13. 